\title{
Synthesis and Properties of ZnO Nano-ribbon and Comb Structures
}

\author{
Y.H. Leung, A. B. Djurišić, and M. H. Xie \\ Dept. of Physics, The University of Hong Kong, Hong Kong, Hong Kong SAR, PR China
}

\begin{abstract}
ZnO}$ is of great interest for photonic applications due to its wide band gap (3.37 eV) and large exciton binding energy $(60 \mathrm{meV})$. A large variety of fabrication methods and nanostructure morphologies was reported up to date for this material. Obtained morphologies include nanobelts or nanoribbons, nanowires, nanorods, tetrapod nanostructures, etc. Novel nanostructures like hierarchical nanostructures, nanobridges and nanonails have also been fabricated. In this work, we report a simple method for fabrication of nanoribbon and nanocomb structures. The structures are fabricated by evaporation of a mixture of $\mathrm{ZnO}$ and carbon nanotubes $(\mathrm{CNT})$ at $1050^{\circ} \mathrm{C}$, and the deposition products have been collected on $\mathrm{Si}$ substrates in the temperature range $750-800^{\circ} \mathrm{C}$. The growth mechanism of obtained structures is discussed.
\end{abstract}

\section{INTRODUCTION}

The wide band gap $(3.37 \mathrm{eV})$ and large exciton binding energy $(60 \mathrm{meV})$ make zinc oxide $(\mathrm{ZnO})$ a promising material for photonic applications, especially in UV or blue spectral range. A wide range of nanostructures has been reported for $\mathrm{ZnO}$, such as nanowires [1], tetrapod nanorods [2], nanoribbons/belts [1-3] etc. Recently, some novel ZnO nanostructures like nanobridges/nails [4] and nanosheets [5] have also been demonstrated. Among all the morphologies, ribbon/comb-like structures are of great interest for the application in nanosized devices due to the ease in manipulation, their welldefined geometry and excellent crystallinity. Recently, UV lasing from nanoribbons has been reported $[6,7]$. Comb-like nanostructures are also interesting for nano-cantilever arrays.

A number of ways to synthesize $\mathrm{ZnO}$ nanoribbon/belts have been reported. Most of the processes require high temperature $\left(900^{\circ} \mathrm{C} \sim 1400^{\circ} \mathrm{C}\right)$, precise pressure, gas flow and composition control $[2,3,5]$. In this work, we report a simple synthesis method for the fabrication of ribbon/comb-like $\mathrm{ZnO}$ nanostructures. $\mathrm{ZnO}$ nanoribbons/combs were fabricated by heating a mixture of $\mathrm{ZnO}$ powder (Aldrich, 99.99\% purity) and single-walled carbon nanotubes (SWCNTs) (Carbolex, AP grade) in a tube furnace at $1050^{\circ} \mathrm{C}$. The whole process took place in ambient atmosphere. After the desired temperature was reached, a quartz tube containing the powder mixture and the substrates $(\mathrm{Si}\{111\}$, rough or polished side) was inserted into a tube furnace. The nanostructures were deposited on the substrates which covered a temperature range of $750-800^{\circ} \mathrm{C}$. The deposited materials were examined by scanning electron microscopy (SEM) using LEO 1530 FESEM, transmission electron microscopy (TEM) and selected area electron diffraction (SAED) using Philips Tecnai 20 TEM, X-ray diffractometry (XRD) using Siemens D5000 X-ray diffractometer, and photoluminescence (PL) using a $\mathrm{HeCd}$ laser excitation source (325 nm).

\section{RESULTS AND DISCUSSIONS}

Figure 1 shows the representative SEM images of the $\mathrm{ZnO}$ nano-ribbon/comb structures grown on the rough back side of a $\mathrm{Si}$ substrate at source temperature of $1050^{\circ} \mathrm{C}$. Bunches of nanoribbon/comb structures covered the surface of the substrate as shown in Figure 1a. The typical widths of the nanostructures are in the range of 3 to $5 \mu \mathrm{m}$, while the lengths are about $10 \mu \mathrm{m}$ in average. Figure $1 \mathrm{~b}$ shows a comb-like structure similar to the dentritic structures which eventually result in a nanosheet structure [5]. A growth mechanism called "1D branching and 2D filling" was proposed for the formation of sheet-like nanostructures [5]. Sidebranching on the basal 1D nanowires results in the formation of a dendritic structure. Such dendritic sidebraching is related to the supersaturation of reactant vapors [5]. It is followed by the planar filling 
of the interspaces between the sidebranches, which is attributed to the selective condensation of vapors on the concave corner sites between the branches [5].

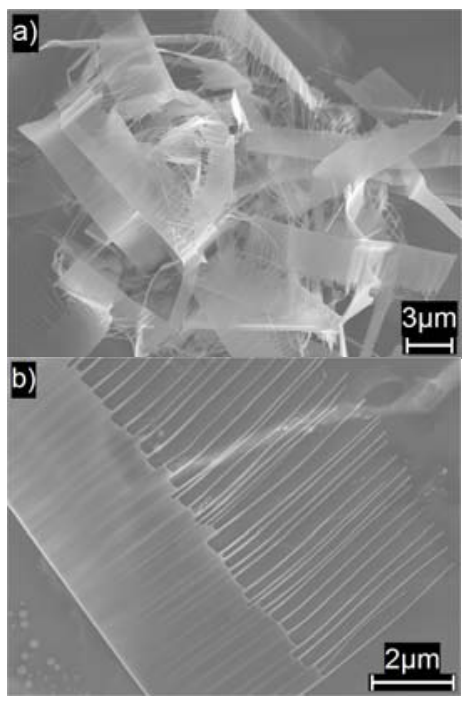

FIGURE 1. Representative images of $\mathrm{ZnO}$ nanoribbons/ combs grown at $1050^{\circ} \mathrm{C}$ on rough $\mathrm{Si}$ surface. a) bunch of nanoribbon/comb structures at low magnification, b) comb nanostructure.

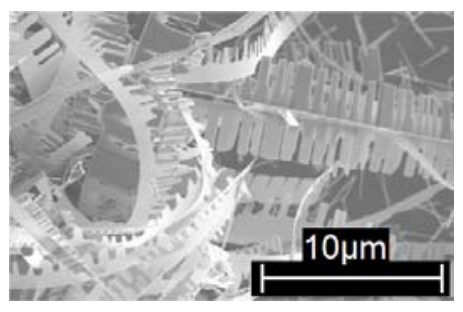

FIGURE 2. SEM image of $\mathrm{ZnO}$ nanoribbons/combs fabricated at $1050^{\circ} \mathrm{C}$ on smooth $\mathrm{Si}$ substrate.

Figure 2 shows the obtained nanostructures on the polished sides of $\mathrm{Si}$ substrates. The branches have relatively equal length and they are very broad. It can be observed that the substrate used in the synthesis has significant effect on the morphologies of the resulting nanostructures. It was also observed that higher yield of nanostructures was obtained using rough $\mathrm{Si}$ substrates, compared to the smooth ones. This can be attributed to the larger number of possible nucleation sites. The differences in the available nucleation sites and $\mathrm{Zn}$ diffusion rates on different substrates affect the subsequent growth of the nanostructures.

Figure 3 shows the photoluminescence (PL) spectra of the obtained nanostructures. Strong UV emission was observed both at room temperature (298K) and $11 \mathrm{~K}$, while the defect-related green emission was much weaker for all the ribbon/comb morphologies.
The shift of the high energy peak with increasing temperature is in agreement with the other works in the literature [8], while the fine structure in the UV emission at $11 \mathrm{~K}$ can be attributed to the free and bound exciton transitions [8].

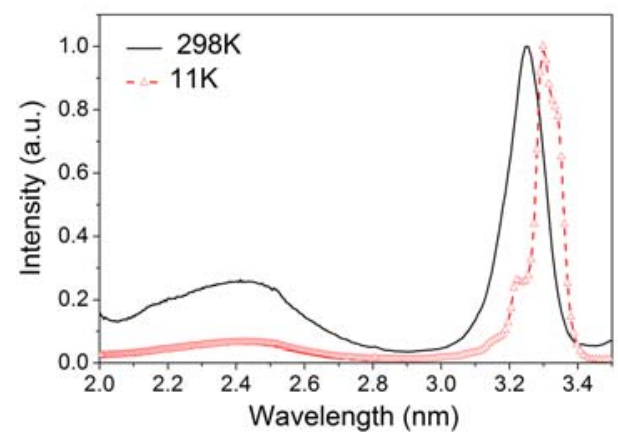

FIGURE 3. Photoluminescence (PL) spectra of the $\mathrm{ZnO}$ nanoribbon/combs.

\section{CONCLUSIONS}

$\mathrm{ZnO}$ ribbon/comb-like nanostructures were prepared at atmospheric pressure using a simple synthesis method. The morphologies were affected by the substrate type. Fabricated ribbon/comb structures exhibited strong UV but week green emission.

\section{ACKNOWLEDGMENTS}

This work is supported by the University of Hong Kong University Research Committee seed funding grant.

\section{REFERENCES}

1. B. D. Yao, Y. F. Chan, and N. Wang, Appl. Phys. Lett. 81, 757-759 (2002).

2. H. Yan, R. He, J. Pham, and P. Yang, Adv. Mater. 15, 402-405 (2003).

3. Z. W. Pan, Z. R. Dai, and Z. L. Wang, Science 291, 1947-1949 (2001).

4. J. Y. Lao, J. Y. Huang, D. Z. Wang, and Z. F. Ren, Nano Lett. 3, 235-238 (2003).

5. J.-H. Park, H.-J. Choi, Y.-J. Choi, S.-H. Sohn, and J.-G. Park, J. Mater. Chem. 14, 35-36 (2004).

6. H. Yan, J. Johnson, M. Law, R. He, K. Knuten, J. R. McKinney, J. Pham, R. Saykally, and P. Yang, Adv. Mater. 15, 1907-1911 (2003).

7. J. A. Zapien, Y. Jiang, X. M. Meng, W. Chen, F. C. K. $\mathrm{Au}$, Y. Lifshitz, and S. T. Lee, Appl. Phys. Lett. 84, 1189-1191 (2004).

8. B. P. Zhang, N. T. Binh, and Y. Segawa, K. Wakatsuki, and N. Usami, Appl. Phys. Lett. 83, 1635-1637 (2003). 
Copyright of AIP Conference Proceedings is the property of American Institute of Physics. The copyright in an individual article may be maintained by the author in certain cases. Content may not be copied or emailed to multiple sites or posted to a listserv without the copyright holder's express written permission. However, users may print, download, or email articles for individual use. 